\title{
Samenwerken in de kenniseconomie ${ }^{*}$
}

\author{
Ferry Koster
}

\section{Paradox van de kenniseconomie}

De bewering dat de wereld steeds complexer wordt, is een cliché dat we keer op keer tegenkomen in de organisatieliteratuur. Of organisaties daadwerkelijk met steeds meer complexiteit te maken hebben, is maar de vraag. Wel is duidelijk dat zij zich in complexe situaties kunnen bevinden en daar oplossingen voor proberen te vinden. De opkomst van kenniseconomie (Powell \& Snellman, 2004) is daar direct aan gerelateerd. In die kenniseconomie wordt informatie gezien als een van de productiefactoren die organisaties nodig hebben naast fysiek, menselijk en sociaal kapitaal. Een interessant kenmerk van informatie is dat het delen ervan nuttig is vanuit het oogpunt van innovatie. Door informatie te verwerken en nuttig te maken voor organisaties, wordt het omgezet in kennis die partijen kunnen inzetten. Het delen van kennis wordt echter door twee zaken belemmerd (Koster, 2016).

Ten eerste wordt het delen ervan beperkt door de mate waarin de kennis grijpbaar is. Concrete kennis is eenvoudig te delen, maar draagt minder bij aan vernieuwingen dan zogenoemde 'onbewuste kennis' ('tacit knowledge') (Polanyi, 1958). Een onderscheidend kenmerk van dit type kennis is dat het niet direct beschikbaar is, maar een onderdeel vormt van de routines van individuen en soms zelfs van teams en organisaties. Het idee is hier dat juist ongrijpbare kennis van grote meerwaarde is in de kenniseconomie.

Ten tweede vormt de diversiteit van actoren een belemmering voor het delen van kennis. Voor organisaties wordt die diversiteit gevormd door de partijen met wie zij interacteren in hun netwerk (Pittaway, Robertson, Munir, Denyer, \& Neely, 2004). Hierbij kan het bijvoorbeeld gaan om toeleveranciers, andere producenten en zelfs concurrenten. Daarnaast kan zowel binnen de keten als daarbuiten worden samengewerkt. Ten slotte zijn diverse partijen te onderscheiden die samenwerkingen kunnen faciliteren (zoals verenigingen en consultants). Hier geldt dat in een kenniseconomie diversiteit van informatie van belang is, omdat op die manier nieuwe ideeën ontwikkeld kunnen worden.

En zo is de kenniseconomie omgeven met de volgende paradox. Enerzijds zou de opbrengst het hoogst zijn als onbewuste kennis gedeeld wordt door organisaties die zoveel mogelijk van elkaar verschillen. Op die wijze wordt namelijk toegang gekregen tot nieuwe kennis. Anderzijds geldt dat juist het delen van onbewuste

* Prof. dr. F. Koster is als universitair hoofddocent Arbeid, Organisatie en Management verbonden aan de afdeling Bestuurskunde en Sociologie van de Erasmus Universiteit Rotterdam. Van 2015-2018 was hij bijzonder hoogleraar Innovatieve Samenwerking aan TIAS School for Business and Society in Tilburg. 
Figuur 1 Samenwerkingsverbanden als netwerken

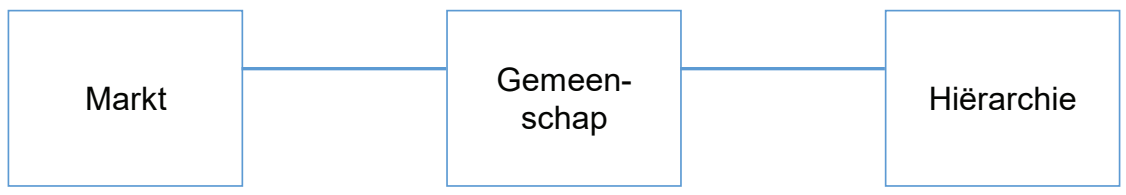

kennis lastig is, vooral tussen organisaties die van elkaar verschillen. De vraag is daarom ook op welke wijze organisaties hun samenwerkingsverbanden kunnen inrichten om de twee genoemde belemmeringen te overwinnen.

\section{Besturen in de kenniseconomie}

In de basis zijn er drie ideaaltypische besturingsvormen die organisaties kunnen kiezen als zij toegang willen krijgen tot nieuwe kennis en kennis willen delen met anderen. Dat zijn: (1) de markt (het prijsmechanisme), (2) de hiërarchie (het autoriteitsmechanisme), en (3) de gemeenschap (het vertrouwensmechanisme). De discussie over samenwerkingsverbanden is lange tijd gedomineerd door de vraag onder welke omstandigheden organisaties voor de markt of voor de hiërarchie kiezen. Volgens die benadering houden samenwerkingsverbanden het midden tussen eenmalige marktrelaties en complete integratie binnen de grenzen van een enkele organisatie (Contractor \& Lorange, 2002). Dat het delen van kennis niet volledig wordt overgelaten aan de markt en niet volledig wordt geïntegreerd, is theoretisch goed te begrijpen: naarmate kennis ongrijpbaarder is, is de kans op marktfalen groter en als de kennisdeling volledig wordt geïnternaliseerd, is de kans groot dat wordt ingeboet aan diversiteit.

In de loop der tijd is het idee ontstaan dat verbanden die zich tussen markten en hiërarchieën bevinden niet zozeer een mengsel van prijs en autoriteit zijn, maar op basis van een eigen mechanisme werken, namelijk vertrouwen. Tussen markten en hiërarchieën blijken zich bijvoorbeeld gemeenschappen te bevinden die bestaan uit relationele contracten (Powell, 1990; Ring \& Van de Ven, 1992). Figuur 1 geeft dit schematisch weer. Langs de dimensie van externalisering en internalisering zijn marktrelaties volledig extern en bureaucratische relaties volledig geïnternaliseerd. Gemeenschapsrelaties zijn volgens deze benadering ten dele geëxternaliseerd.

\section{Substitutie versus complementariteit van mechanismen}

Zodra aangenomen wordt dat een samenwerkingsverband op basis van de drie mechanismen kan functioneren, ontstaat een volgend punt van discussie, namelijk of die drie mechanismen substituten zijn of dat zij complementair kunnen zijn (Poppo \& Zenger, 2002; Gulati \& Nickerson, 2008; Ryall \& Sampson, 2009; Weber \& Mayer, 2011). Als de mechanismen substituten zijn, vervangen zij elkaar 
(zoals weergegeven in figuur 1), als zij complementair zijn, versterken zij elkaar. In die gedachte worden vertrouwensrelaties niet ondermijnd door formele contracten, maar zou de combinatie van vertrouwen en controle de relatie tussen partijen kunnen versterken. De praktijk laat zien dat er combinaties voorkomen. Zo geven Bradach en Eccles (1989) een overzicht van studies waaruit blijkt dat binnen markten hiërarchische mechanismen kunnen ontstaan en dat omgekeerd het prijsmechanisme wordt toegepast binnen organisaties. Vanuit een ander startpunt, namelijk dat van variaties in bureaucratieën, voegen Adler en Borys (1996) toe dat binnen een hiërarchie sprake kan zijn van vertrouwen en wantrouwen. Zij laten zien dat er zowel beperkende bureaucratieën als faciliterende bureaucratieën bestaan (Adler \& Borys, 1996). Hoewel de praktijk laat zien dat zowel substitutie en complementariteit mogelijk is, valt er iets voor te zeggen dat complementariteit juist van belang is in de kenniseconomie.

\section{Pluriformiteit van samenwerkingsverbanden}

Als wordt uitgegaan van complementariteit van de mechanismen, dan luidt de conclusie dat een samenwerkingsverband tussen organisaties niet per se op basis van vertrouwen functioneert. Dit idee is terug te vinden in een exploratief artikel van Adler uit 2001. In plaats van aan te nemen dat er automatisch substitutie van markt, hiërarchie en vertrouwen plaatsvindt, beredeneert hij wat er gebeurt als er mengvormen kunnen ontstaan, niet alleen van markt en hiërarchie maar ook van alle drie de mechanismen. In dat model vormen deze mechanismen drie dimensies waarop beheersstructuren kunnen worden ingedeeld, wat resulteert in acht opties. Door dat te doen verheldert hij een groot deel van de discussie over deze mechanismen. De volgende twee figuren (figuur 2 en figuur 3) geven de acht opties weer.

In figuur 2 staan de vier samenwerkingsverbanden waarbij vertrouwen als besturingsmechanisme ontbreekt. Linksonder vinden we hier de optie waarbij het verband ook geen marktmechanismen of hiërarchische sturing kent. Voorbeelden van deze 'asociale horde' zijn enerzijds partijen die net een verband zijn gestart, nog niet eerder met elkaar hebben samengewerkt en geen afspraken op papier hebben gezet. Anderzijds kan deze vorm zich voordoen aan het eind van een samenwerking, als blijkt dat het niet meer werkt, er geen vertrouwen (meer) is en formele regels niet worden onderschreven door de partijen. De 'spotmarkt' is de situatie waarin producten en diensten puur op basis van prijzen worden uitgewisseld. Dit houdt in dat partijen kennis inkopen van anderen. Het leidende principe hierbij is dat op het moment dat een andere partij dezelfde kennis voor een lagere prijs kan leveren, zal worden overgestapt naar die partij. Loyaliteit speelt daarbij dus geen rol. De 'dwingende bureaucratie' wil zeggen dat partijen een verband aangaan waarin het onderlinge wantrouwen wordt beteugeld door wederzijds regels op te leggen waaraan partijen zich dienen te houden. Kenmerkend voor deze oplossing is dat partijen beperkt worden door deze regels. Op die manier wordt bijvoorbeeld voorkomen dat zij misbruik kunnen maken van elkaars inspanningen. Onderlinge controle is daarbij het leidende principe. Samenwer- 


\section{Figuur 2 Samenwerkingsverbanden waarin vertrouwen ontbreekt}

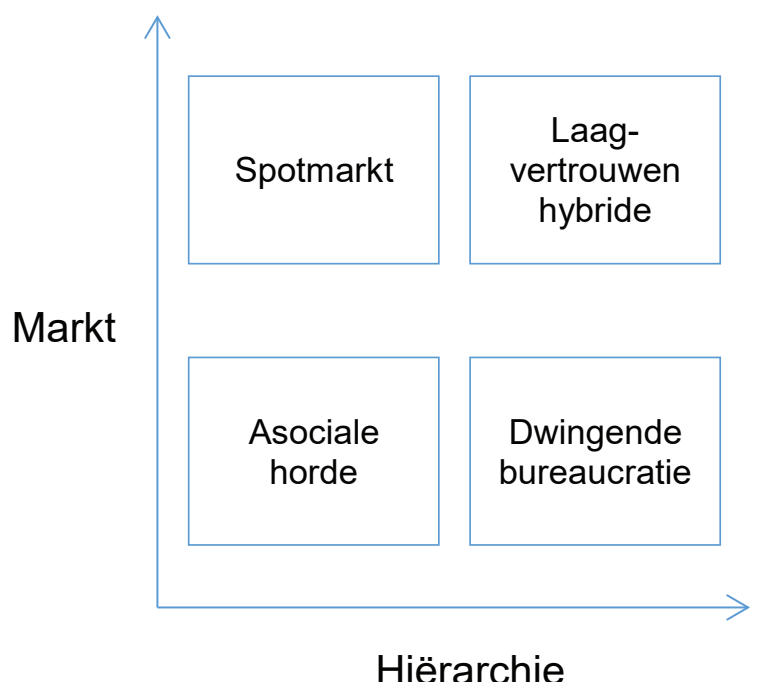

Bron: Adler (2001)

kingsverbanden van het 'laag-vertrouwen hybride' type combineren prijsprikkels met dergelijke beperkende regels. Kortom, in principe werkt de markt hier, maar de partijen leggen elkaar evenals bij de dwingende bureaucratie beperkingen op.

Figuur 3 geeft de mogelijkheden weer als partijen elkaar wel vertrouwen. Samenwerkingsverbanden die puur op basis van vertrouwen werkzaam zijn, worden 'clans' genoemd. Het succes van deze verbanden is erin gelegen dat er sterke onderlinge normen zijn over het bijdragen aan het verband en hoe er met elkaar wordt omgegaan. In het geval van 'relationele contracten' blijft het marktprincipe intact, maar speelt loyaliteit ook een rol. Dat betekent bijvoorbeeld dat bij een nieuwe klus de kans groot is dat met dezelfde partij zaken wordt gedaan. De 'faciliterende bureaucratie' werkt op basis van regels die ondersteunend zijn voor de samenwerking, wat mogelijk is doordat sprake is van onderling vertrouwen. De 'hoog-vertrouwen hybride', ten slotte, combineert prijs, hiërarchie en vertrouwen.

De aanpak van Adler (2001) levert belangrijke nieuwe inzichten op, zowel voor de bestudering van transacties in het algemeen als voor samenwerkingsverbanden tussen organisaties. Waar eerdere benaderingen alleen de spotmarkt, de dwingende bureaucratie en de clan onderscheiden, volgt uit dit model dat er andere combinaties mogelijk zijn. Daarmee verheldert het in één oogopslag een aantal discussies. Zo is te zien dat de analyse van samenwerkingsverbanden zich vrij eenzijdig heeft gericht op verbanden die gebaseerd zijn op een gebrek aan vertrouwen. Veel van deze literatuur is te plaatsen in figuur 2 Daar staat tegenover 
Figuur 3 Samenwerkingsverbanden met vertrouwen

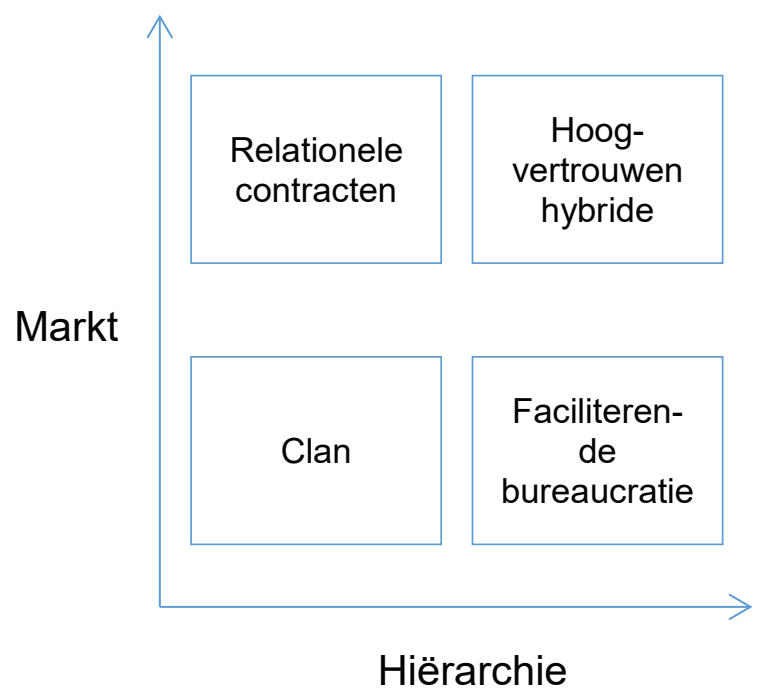

Bron: Adler (2001)

dat de literatuur die vertrouwen centraal stelt, eenzijdig is in die zin dat het zich voornamelijk richt op clan-relaties. Aan de hand van het door Alder voorgestelde model kunnen relationele contracten (een combinatie van prijs en vertrouwen) (Ring \& Van de Ven, 1992) eenvoudig worden ingepast. Daarnaast wijst dit model erop dat Ouchi's (1980) impliciete aanname dat de clan 'als vanzelf' tot solidariteit en doelcongruentie zou leiden problematisch is, aangezien een clan ook kan verworden tot een asociale horde.

\section{De samenwerkingsgemeenschap in de praktijk}

Het voorgaande is voornamelijk een theoretische exercitie en dat roept de vraag op hoe waarschijnlijk het is dat samenwerkingsverbanden inderdaad kenmerken van een samenwerkingsgemeenschap vertonen en onder welke omstandigheden markt, hiërarchie en vertrouwen gecombineerd worden. Een eerste aanwijzing daarvoor kwam naar voren in verkennende gesprekken die we in Kenniscentrum ICOON ('Innoveren, Coöpereren en Ondernemen') voerden met ondernemers. Zo vertelde een installateur dat het minder vaak het geval was dat een publieke partij als de gemeente eenvoudigweg een traplift bij hen inkocht. In plaats daarvan kwam het meer voor dat zij aan tafel zaten met de gemeente en burgers om tot gezamenlijke oplossingen te komen. Kortom, hier leek een verschuiving plaats te vinden van een pure marktrelatie (het inkopen van een traplift) naar een situatie waarin marktpartijen, bureaucratieën en gemeenschap naar oplossingen gingen zoeken. Wellicht is dit een model op basis waarvan gewerkt kan worden aan maat- 
schappelijke vraagstukken die de inzet van verschillende soorten organisaties vereisen. Denk bijvoorbeeld ook aan de energietransitie of andere uitdagingen als een droogkokende woningmarkt en de toekomst van de arbeidsmarkt.

Om erachter te komen of samenwerkingsverbanden tussen organisaties lijken op samenwerkingsgemeenschappen, is vervolgens een pilotstudie uitgevoerd waarin een vragenlijst is getest onder zeventig organisaties (Koster, Korte \& Van de Goorbergh, 2016). Deze vragenlijst bevatte items waarmee werd getracht de samenwerkingsrelaties tussen organisaties op het gebied van personeelsbeleid in kaart te brengen aan de hand van een zestal vragen. Die zes vragen waren er gezamenlijk op gericht de drie mechanismen te meten. Hoewel de dataset redelijk klein is, bleek het toch mogelijk om een aantal conclusies te trekken. Ten eerste bleek na een factoranalyse en een betrouwbaarheidsanalyse dat de zes items een schaal vormen (de Cronbach's alfa was 0,82 ). Dit levert een ondersteuning op voor het idee dat die drie sturingsmechanismen eerder complementair zijn dan substituten vormen, anders zouden meerdere dimensies gevonden zijn en dat was niet het geval. Ten tweede bleek de toepassing van de samenwerkingsgemeenschap door organisaties gerelateerd te zijn aan de innovativiteit van de organisatie, wat suggereert dat deze samenwerkingsvorm daadwerkelijk bijdraagt aan vernieuwingen op het gebied van producten en diensten. Dit vormt een aanvulling op de constatering dat samenwerking tussen organisaties samengaat met innovaties op verschillende terreinen (Pouwels \& Koster, 2017), omdat het onderschrijft dat het niet alleen gaat om dat er wordt samengewerkt, maar dat het ook uitmaakt op welke de wijze het samenwerkingsverband is ingericht. Ten derde bleek de samenwerkingsgemeenschap vooral voor te komen bij organisaties waarin technologische ontwikkeling gepaard gaat met complexere taken, die gericht zijn op de ontwikkeling van menselijk kapitaal binnen hun organisatie, en die trainingen aanbieden die gericht zijn op het vergroten van de kwaliteit van producten en diensten. Deze uitkomst onderschrijft het idee dat de noodzaak voor het combineren van markt, hiërarchie en vertrouwen toeneemt zodra kennis een meer centrale plek inneemt in organisaties.

In een tweede studie (Koster \& Bloem, 2019) stelden we de vraag of een combinatie van prijs, autoriteit en vertrouwen bijdraagt aan innovativiteit van organisaties. In dit onderzoek maakten we gebruik van een vignettenonderzoek waarin de drie besturingsmechanismen de onderzoekscondities waren en aan respondenten werd gevraagd een inschatting te maken van de waarschijnlijkheid dat het tot innovatie (in product, proces, markt en organisatie) zou leiden. Op basis van 147 ingevulde vignetten bleek het volgende. Om te beginnen kwam naar voren dat de kans op innovatie het hoogst werd ingeschat in het geval van de samenwerkingsgemeenschap. Echter, deze score week niet significant af van de andere opties waarin sprake is van vertrouwen (de clan, de faciliterende bureaucratie en relationele contracten). Voor dit moment kan dus niet worden gesteld dat de samenwerkingsgemeenschap de enige manier is om innovaties tot stand te brengen. Wat wel gesteld mag worden, is dat het vertrouwensmechanisme in deze studie van doorslaggevend belang was. Een vergelijking van de opties met en zonder vertrou- 
wen (oftewel tussen de vormen die zijn weergegeven in figuur 2 en figuur 3) leverde over het geheel genomen het inzicht op dat de vormen met vertrouwen eerder tot innovatie zullen leiden dan die zonder vertrouwen. Wat dit vooral laat zien, is dat er niet één optimale manier hoeft te zijn om innovaties tot stand te brengen, maar dat verschillende mengvormen tot hetzelfde doel kunnen leiden. In ieder geval, zolang er zorggedragen wordt voor voldoende vertrouwen tussen de verschillende partijen.

Daarmee geeft het onderzoek een eerste inkijk in de paradox van de kenniseconomie. Dat niet alle samenwerkingsverbanden een combinatie van markt, hiërarchie en vertrouwen zijn, geeft al aan dat het niet de meest eenvoudige vorm van samenwerken is. Dat het vooral voorkomt in situaties waarin complexere problemen een rol spelen, geeft aan dat de combinatie van de besturingsmechanismen een rol kunnen spelen in het oplossen ervan.

\section{Literatuur}

Adler, P.S. (2001). Market, hierarchy, and trust: The knowledge economy and the future of capitalism. Organization Science, 12(2), 215-234.

Adler, P.S., \& Borys, B. (1996). Two types of bureaucracy: Enabling and coercive. Administrative Science Quarterly, 41(1), 61-89.

Bradach, J.L., \& Eccles, R.G. (1989). Price, authority, and trust: From ideal types to plural forms. Annual Review of Sociology, 15, 97-118.

Contractor, F.J., \& Lorange, P. (2002). The growth of alliances in the knowledge-based economy. International Business Review, 11(4), 485-502.

Gulati, R., \& Nickerson, J.A. (2008). Interorganizational trust, governance choice, and exchange performance. Organization Science, 19(5), 688-708.

Koster, F. (2016). Zelf doen is optellen, samenwerken is vermenigvuldigen. Organisaties, relaties, innovaties. Tilburg: TIAS.

Koster, F., \& Bloem, D. (2019). "Have a little faith". A vignette study of inter-organizational cooperation and innovation performance. International Journal of Business Science and Applied Management, 13(1), 25-41.

Koster, F., Korte, M., \& Goorbergh, P. van de. (2016). Innovatief personeelsbeleid en samenwerking tussen organisaties: Resultaten van een pilotstudie. ICOON Paper 6. Tilburg: ICOON.

Ouchi, W.G. (1980). Markets, bureaucracies, and clans. Administrative Science Quarterly, 25(1), 129-141.

Pittaway, L., Robertson, M., Munir, K., Denyer, D., \& Neely, A. (2004). Networking and innovation: A systematic review of the evidence. International Journal of Management Reviews, 5/6, 137-168.

Polanyi, M. (1958). Personal knowledge: Towards a post-critical philosophy. Chicago: University of Chicago Press.

Poppo, L., \& Zenger, T. (2002). Do formal contracts and relational governance function as substitutes or complements? Strategic Management Journal, 23(8), 707-725.

Pouwels, I., \& Koster, F. (2017). Inter-organizational cooperation and organizational innovativeness. A comparative study. International Journal of Innovation Science, 9(2), 184-204. 
Ferry Koster

Powell, W.W. (1990). Neither market nor hierarchy: Network forms of organization. Research in Organizational Behavior, 12, 295-336.

Powell, W.W., \& Snellman, K. (2004). The knowledge economy. Annual Review of Sociology, 30, 199-220.

Ring, P.S., \& Ven, A.H. van de. (1992). Structuring cooperative relationships between organizations. Strategic Management Journal, 13(7), 483-498.

Ryall, M.D., \& Sampson, R.C. (2009). Formal contracts in the presence of relational enforcement mechanisms: Evidence from technology development projects. Management Science, 55(6), 906-925.

Weber, L., \& Mayer, L.J. (2011). Designing effective contracts: Exploring the influence of framing and expectations. Academy of Management Review, 36(1), 53-75. 